\title{
"Somos cuerpo, alma y espíritu": Persona, enfermedad y procesos de sanación y exorcismo en el catolicismo contemporáneo en Argentina
}

\author{
"We are body, soul and spirit": Person, disease and \\ processes of healing and exorcism in contemporary \\ Catholicism in Argentina
}

Verónica Giménez Béliveau', Natalia Soledad Fernández ${ }^{2}$

${ }^{1}$ Doctora en Sociología. Investigadora independiente, Centro de Estudios e Investigaciones Laborales Consejo Nacional de Investigaciones Científicas y Técnicas (CEIL-CONICET) Ciudad Autónoma de Buenos Aires, Argentina. $\triangle$ (iD

2Estudiante de Doctorado en Sociología, Universidad Nacional de San Martín. Becaria, Centro de Estudios e Investigaciones Laborales, Consejo Nacional de Investigaciones Científicas y Técnicas (CEIL-CONICET), Ciudad Autónoma de Buenos Aires, Argentina. $\triangle$ iD
RESUMEN En la intersección entre religión y salud, las demandas de sanación, liberación y exorcismo expresan malestares indefinidos que van desde afecciones físicas y psiquiátricas hasta problemas psicológicos y relacionales. Para comprender esta demanda creciente, este estudio se propone analizar, por un lado, las concepciones de persona y enfermedad y, por otro, las terapéuticas que los sacerdotes y sus asistentes ponen en funcionamiento, a partir de una investigación etnográfica con observación participante y entrevistas en profundidad realizadas entre 2013 y 2017 en parroquias de la ciudad de La Plata y otras localidades de la provincia de Buenos Aires. Los resultados nos permiten comprender que la concepción de persona -sobre la cual se desarrollan las terapéuticas- supone un ensanchamiento del individuo hacia los planos físico, psicológico y espiritual, y que las nociones de enfermedad y bienestar abarcan a la persona, a su entorno y a las generaciones pasadas. PALABRAS CLAVES Religión; Terapéutica; Argentina.

ABSTRACT At the intersection of religion and health, demands for healing, liberation and exorcism express undefined discomforts that span from physical and psychiatric conditions to relational and psychological problems. To understand this growing demand in the population, this study seeks to analyze, on the one hand, the underlying conceptions of person and disease and, on the other, the therapeutics that priests and their assistants put into action, based on an ethnographic study with participant observation and in-depth interviews carried out between 2013 and 2017 in parishes in the city of La Plata and other localities of the province of Buenos Aires. The results enable us to understand that the conception of person based upon which therapeutic actions are carried out involves an expansion of the individual to the physical, psychological and spiritual planes, and that the notions of disease and wellbeing include the person, their environment and past generations.

KEY WORDS Religion; Therapeutics; Argentina. 


\section{INTRODUCCIÓN}

En 2013, a partir del trabajo de campo realizado en parroquias de Buenos Aires y su periferia, nos Ilamó la atención la presencia de rituales de exorcismo y liberación. La idea de pensar la convivencia de rituales de expulsión de espíritus del mal en comunidades católicas carismáticas ${ }^{(1,2)}$, que centraban sus prácticas alrededor de la salud y la sanación, generó una serie de preguntas sobre las definiciones socialmente operativas de la salud, el malestar y la enfermedad, y sobre la interacción de los procesos de curación biomédicos y las terapéuticas católicas. En este campo, de hecho, las fronteras entre la religión y la medicina son lábiles, las terapéuticas se entrecruzan y dialogan entre ellas, y la eficacia de los rituales es a menudo evocada por médicos y psiquiatras.

A partir de la década de 1980 surgió desde la antropología de la medicina una serie de interrogantes sobre el sentido del síntoma, y proponían una etnografía de la enfermedad y de las terapéuticas, restituyendo un sentido social y cultural a las prácticas alrededor del malestar, la enfermedad y la cura $^{(3)}$. Incluso la relación entre la enfermedad, el dolor y la muerte es revisitada en función de resituarla en un contexto social, para mostrar las maneras en que la comunidad modela y da sentido a formas particulares de procesar el dolor ${ }^{(4)}$.

El ritual del exorcismo remite, en el sentido común, a prácticas situadas temporalmente en épocas oscuras marcadas por el dominio de una Iglesia que ejercía el control de las vidas, los cuerpos y las sexualidades; y ha sido examinado por las ciencias sociales desde una perspectiva histórica ${ }^{(5,6,7,8)}$ atribuyendo a los fenómenos de posesión y expulsión de los demonios la expresión de malestares sociales. En el campo de los estudios sociológicos y antropológicos, el análisis de las prácticas de exorcismo ha sido abordado etnográficamente por Talamonti ${ }^{(9)}$ en Italia, quien trabaja la dimensión corporal de la posesión-expulsión de entidades; Amiotte-Suchet ${ }^{(10)}$ se pregunta por las interacciones entre concepciones psicológicas y espirituales en las prácticas de un exorcista diocesano en Francia; Giordan y Possamai ${ }^{(11)}$ analizan las interacciones entre exorcismo y prácticas Nueva Era, y Csordas ${ }^{(12,13)}$ integra el ritual de exorcismo en procesos más amplios relacionados con la cura y la salvación.

En América Latina, los fenómenos de posesión y exorcismo en contextos neopentecostales (especialmente, en el caso de la Iglesia Universal del Reino de Dios) han suscitado interés en diversos campos académicos. Ribeiro $^{(14)}$ analiza rituales de liberación y cura de la Iglesia Universal en tanto dispositivos discursivos de construcción de alteridad, y destaca los artefactos rituales y discursivos que oponen a esta Iglesia con los grupos afrobrasileños, en el marco de un esquema cosmológico binario que alinea a unos con el bien y a otros con el mal. De Almeida ${ }^{(15)}$ analiza la posesión en la Iglesia Universal, y destaca que la figura del diablo y el juego de oposiciones que despierta es uno de los ejes que han permitido su espectacular crecimiento; mientras que Semán y Moreira ${ }^{(16)}$ y Tadvald ${ }^{(17)}$ trabajan los efectos de los procesos de transnacionalización religiosa en las representaciones del demonio y del mal en una iglesia neopentecostal (la Iglesia Universal del Reino de Dios).

Los sacerdotes que practican exorcismos y los grupos que constituyen dedican gran parte de su tiempo a atender personas que presentan un arco variado de problemas que afectan su salud: desde falta de sueño y miedos recurrentes, hasta erupciones de la piel, malestares digestivos y problemas de relación familiares y laborales. Algunos de estos malestares son atribuidos por los pacientes a intervenciones de agentes no humanos que, provenientes del plano espiritual, afectan el plano corporal: así como propone Tadvald ${ }^{(18)}$ en su estudio sobre el espiritismo kardecista, la experiencia vivida en y desde los cuerpos de los sujetos depende también de la salud espiritual. Esta ligazón íntima entre salud corporal y espiritual se recorre en los dos sentidos, y de allí deriva la importancia que tiene para el catolicismo el cuidado de la salud y el bienestar del cuerpo.

Llegamos a los grupos interesadas por el exotismo de las prácticas, pero rápidamente 
nuestro interés se vio incrementado por la profundidad de un campo que nos permitía pensar la sociedad a partir del análisis de las formas -rituales y clínicas- de tratar malestares modernos.

\section{ABORDAJES METODOLÓGICOS}

Trabajamos con grupos católicos de fieles insertos en parroquias, comprometidos con tareas de sanación y liberación. Los sacerdotes que lideran estos grupos realizan sus prácticas en vínculo con psiquiatras y psicólogos católicos, que conciben sus carreras profesionales como una forma de vocación al servicio de Dios. Las interacciones con el "campo psi" son intensas en forma de lecturas, participación de profesionales y esquemas de trabajo.

Como parte de nuestro trabajo de campo, asistimos a misas de sanación y liberación, retiros y encuentros de formación, observamos días fijos de consulta y registramos encuentros particulares entre los fieles y los sacerdotes, recurriendo a las estrategias de la etnografía ${ }^{(19,20)}$, la entrevista y el análisis de textos. Los casos fueron seleccionados a partir del criterio de búsqueda de casos ricos en información ${ }^{(21,22)}$. Los grupos elegidos en la zona norte del Gran Buenos Aires (San Isidro), en la zona sur (Quilmes y Ezpeleta), en la Ciudad Autónoma de Buenos Aires y en la ciudad de La Plata, fueron etnografiados entre 2013 y 2017. Se realizaron 23 entrevistas dialógicas ${ }^{(23)}$, de las cuales citamos textualmente 14 en este trabajo. Los casos estudiados (Tabla 1) se relacionan de manera más o menos cercana con las versiones renovadas del catolicismo: moderadamente renovadas (Quilmes, San Isidro) y renovada (Ezpeleta, Ciudad de Buenos Aires). Aunque el grupo de La Plata se aleja de la corriente institucional carismática, en todos los casos se observan creencias y prácticas afines a lo que podríamos llamar un proceso de "carismatización" del catolicismo, presente con distintos grados de intensidad: la incorporación de

Tabla 1. Selección de personas entrevistadas, citadas en esta investigación, según actividad, fecha de realización de la entrevista y localidad. Buenos Aires, 2013-2017.

\begin{tabular}{llll} 
Nombre ficticio & Actividad & Fecha & Localidad \\
\hline Padre B & Sacerdote exorcista & $28-01-2013$ & Quilmes, Buenos Aires \\
Padre A & Sacerdote exorcista & $02-08-2013$ & La Plata, Buenos Aires \\
Juan & Asistente del padre A & $02-08-2013$ & La Plata, Buenos Aires \\
Carlos & Asistente del padre A & $02-08-2013$ & La Plata, Buenos Aires \\
Padre B & Sacerdote exorcista & $19-11-2014$ & Quilmes, Buenos Aires \\
Iván M & Psiquiatra & $28-11-2014$ & Ciudad Autónoma de Buenos Aires \\
Amalia & Psicóloga y psiquiatra & $01-12-2014$ & Quilmes, Buenos Aires \\
Padre C & Sacerdote exorcista & $13-02-2015$ & San Isidro, Buenos Aires \\
Padre I & Sacerdote exorcista & $25-05-2015$ & Ciudad Autónoma de Buenos Aires \\
Estela & Fiel de la parroquia del padre C & $02-11-2015$ & San Isidro, Buenos Aires \\
Bernadette & Asistente del padre C & $25-11-2015$ & San Isidro, Buenos Aires \\
Padre L & Sacerdote & $07-10-2016$ & Ezpeleta, Buenos Aires \\
Padre L & Sacerdote & $26-02-2017$ & Ezpeleta, Buenos Aires \\
María & Laica comprometida en la parroquia del padre L & $22-05-2017$ & Ezpeleta, Buenos Aires \\
\hline Fuente: Elaboración propia. & & \\
\hline
\end{tabular}


elementos como la creencia en los milagros, los dones espirituales, las sanaciones, el énfasis en el bautismo y en el poder superior del Espíritu Santo, y la representación dominante de un Cristo poderoso y amante que reemplaza al Cristo sufriente, performativizados a través de representaciones dramáticas sostenidas por estilos musicales extendidos y homogeneizados ${ }^{(1,2,24,25,26,27)}$.

Cuatro de los sacerdotes pertenecen al clero secular de las diócesis de San Isidro, Quilmes, Buenos Aires y La Plata, el quinto pertenece a la orden religiosa de los Siervos de María, y está incardinado en la diócesis de Quilmes. Los textos analizados corresponden a materiales que los grupos leen y trabajan en sus retiros y talleres de formación interna: es el caso de los escritos del médico psiquiatra Marcelo Dezzi, referencia ineludible para los sacerdotes y los laicos involucrados en tareas de sanación y liberación, quienes se formaron asistiendo a sus retiros y talleres, y lo citan permanentemente en entrevistas y ceremonias. Se trata de uno de los profesionales más activos en las redes de circulación carismática vinculadas con la sanación y el exorcismo.

El presente artículo forma parte de una investigación más amplia, que las autoras llevan a cabo en el Centro de Estudios e Investigaciones Laborales (CEIL) dependiente del Concejo Nacional de Investigaciones Científicas y Técnicas $\left(\right.$ CONICET) ${ }^{(28)}$. La investigación se ajusta a los lineamientos éticos para las Ciencias Sociales y las Humanidades elaborados por el Comité de Ética del CONICET, Resolución 2857 del Ministerio de Educación, Ciencia y Tecnología. Los grupos y los sujetos contactados fueron informados del carácter exclusivamente académico de nuestra investigación. Las entrevistas se realizaron garantizando la confidencialidad de los informantes que, en todo momento, estuvieron al corriente de los propósitos científicos. En el artículo se trabajó con seudónimos para proteger la confidencialidad de los registros.

El artículo se organiza en dos apartados: en el primero profundizaremos en las teorías nativas sobre la persona, el cuerpo y la enfermedad, en el segundo trabajaremos las terapéuticas que, articuladas con dichas teorías, son practicadas por los grupos estudiados. Este recorrido descubre las interacciones con el discurso biomédico y otros discursos sociales contemporáneos.

\section{RESULTADOS}

\section{El cuerpo permeable: teorías nativas sobre la persona, la enfermedad y el malestar}

La tradición antropológica ha trabajado la noción de persona desde los escritos pioneros de Marcel Mauss ${ }^{(29)}$. Su definición conecta al sujeto con sus pares y también con sus ancestros a través de la dimensión moral, que es centralmente social. Nos plantearemos aquí interrogantes que se inscriben en esta línea de pensamiento: los sujetos con los que trabajamos son portadores de ideas sobre sí mismos, su propio cuerpo y las relaciones sociales que es necesario no dar por supuestas. A qué llamamos persona, cuáles son sus límites, cómo definimos el cuerpo y cuál es el alcance de las terapéuticas son interrogantes que toman por objeto definiciones operativas, vivas, colectivas, en las que se juegan las posibilidades de intervención de los grupos en la salud y el bienestar de sus miembros, y también los límites de estas intervenciones.

Desde la perspectiva de los sujetos con los que trabajamos, el cuerpo está inseparablemente ligado al alma y al espíritu. La persona humana es pensada en tres niveles: el corporal, el psicológico y el espiritual. Estos niveles están indiscerniblemente unidos. Como sostiene el padre $\mathrm{C}$, sacerdote exorcista, "somos unidad de cuerpo, alma, mente y espíritu". En el mismo sentido, el psiquiatra católico Marcelo Dezzi, afirma:

Somos una unidad. Cada parte del cuerpo depende de una central que es el cerebro anatómico; al cual no sólo llega lo puramente orgánico, sino también el alma que forma parte de cada estructura material y que lo anima. ${ }^{(30)}$ 
La persona es, entonces, cuerpo, psique y alma. Las distintas fuentes con las que trabajamos (entrevistas, observaciones de rituales y consultas, textos) reiteran estos tres niveles, aunque los nombran de distintas formas: el psiquiatra que trabaja con el padre A habla de niveles corporal, psicológico y espiritual (Figura 1).

Por su parte, el psiquiatra Marcelo Dezzi se refiere a una bipartición de la persona en cuerpo y alma, que luego del pecado original están separadas por el "inconsciente parapsicológico o puerta del alma"(31). A los asistentes a las consultas con el padre $\mathrm{C}$ les entregan la publicación Consejos pastorales contra la acción extraordinaria del Demonio ${ }^{(32)}$, editada por el equipo de la Pastoral de la Consolación de la Diócesis de San Isidro. En ese folleto, que se llevan a su casa, se explica la relación entre cuerpo y alma afirmando que

...a través del cuerpo se comunica el amor. Sin el cuerpo, el amor quedaría oculto en el alma, y es a través del cuerpo que se fortalece la caridad. Es por esta repercusión en la corporeidad sobre el alma que la manera en que vivas tu sexualidad tiene tanta importancia para una liberación plena. ${ }^{(32)}$

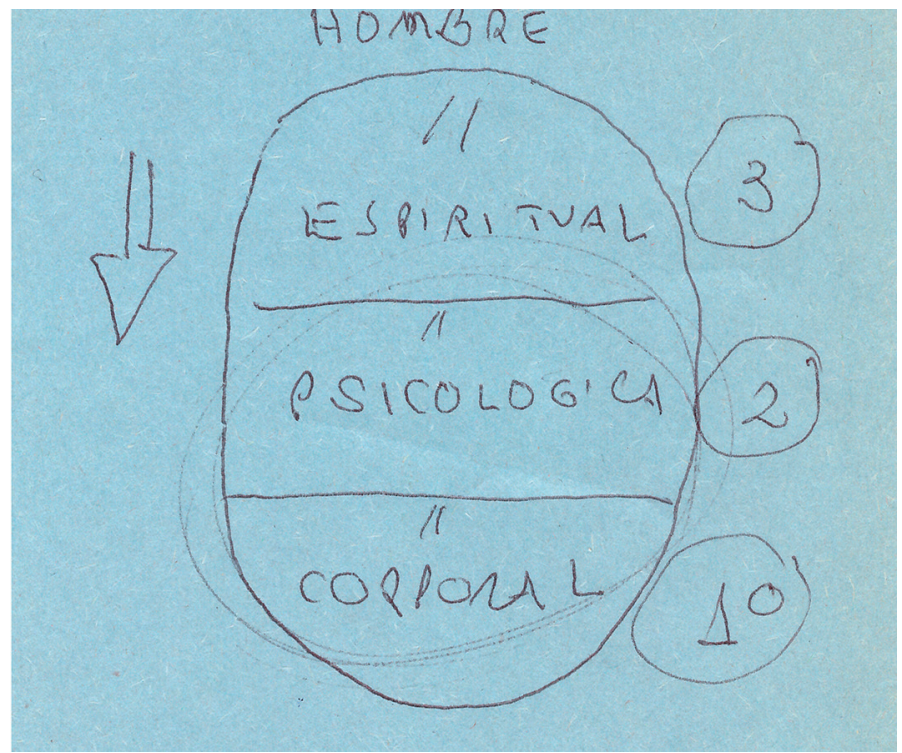

Figura 1. Dibujo que esquematiza a la persona, realizado por el psiquiatra Iván M. 28 de noviembre de 2014.
En este sentido, cuerpo, psiquis y alma no solo forman parte de la unidad de la persona, sino que están relacionados a través de vasos comunicantes que hacen circular sentimientos, enfermedades y malestares entre los distintos niveles: una conducta desordenada que infringe las reglas morales llevará a sufrir malestares físicos y corporales.

Las representaciones de los niveles físico, psicológico y espiritual, en términos de unidad, llevan a los sujetos a pensar los malestares y las enfermedades que los afectan en relación con los distintos niveles. En una larga explicación sobre el origen de las enfermedades, Dezzi argumenta que:

...la voluntad es el motor de la vida, y si ese motor no tiene su centro en Cristo, se diluyen las respuestas [...] Este motor puede tener fallas (llámense enfermedades) orgánicas (depresiones Ilamadas endógenas), que se producen por disminución de neurotransmisores químicos (al reponerlos con medicación mejora esa persona) o espirituales, por apertura del alma a basuras de las tinieblas. En las dos situaciones se "apaga" la voluntad, pero, como vimos, por causas diferentes. A veces se combinan las dos situaciones. ${ }^{(30)}$

Las causas que los agentes atribuyen al origen de la enfermedad se montan, en efecto, sobre la interpretación de la persona: se ubican en el plano del cuerpo, del alma y/o del espíritu. Pero también aparece una fragilización de los sujetos que provoca causalidades mixtas: uno de los psiquiatras que trabajan con el padre A sostiene que:
...los enfermos mentales viven en un estado de híper alerta, algunas patolo- gías, sobre todo, entonces están híper sensibles. $Y$ ellos perciben cosas que por ahí vos no percibís. Entonces son más permeables a estar influenciados por esa contaminación. (Iván M, psiquiatra)

La combinación de enfermedad psiquiátrica (que se ubica en el nivel psíquico) y de apertura hacia mundos suprasensibles (nivel 
espiritual) muestra una concepción de la persona permeable a las influencias naturales y sobrenaturales. El ser humano es poroso y está abierto a distintas influencias. El cuerpo manifiesta el mal que, en su forma extrema de ingreso de espíritus en la persona, se exterioriza a través de manifestaciones físicas: expansión y contracción de las pupilas, movimientos inquietos, eructos, bostezos, erupciones cutáneas, cambio de la temperatura corporal suelen ser evocados por los exorcistas como manifestaciones recurrentes en el momento del diagnóstico. Las consultas a los exorcistas suelen tener origen en malestares expresados de manera indefinida: insomnio, dolores crónicos y/o recurrentes, opresión en el pecho durante la noche, tristeza persistente, ansiedad, visiones y escucha de voces. Los consultantes piensan sus síntomas en términos de enfermedades o alteraciones que superan las posibilidades de acción de la medicina científica.

Siguiendo las definiciones nativas de la persona, los exorcistas y sus colaboradores consideran que los malestares son producto de distintas causas que se ubican en los niveles físico, psíquico y espiritual. La enfermedad es causada por "puertas abiertas" en alguno de los niveles, o en una combinación entre ambos. La puerta, espacio liminal que conecta a la persona con el mundo exterior, es definida incluso como una "hendidura anatómica" que, causada por el pecado original, se cerraría en el momento del bautismo; sin embargo, la persistente tendencia de la persona a cometer pecados reabre el límite a las malas influencias ${ }^{(31)}$. La intervención de la persona y su libre albedrío para elegir entre el bien y el mal es una de las claves para pensar las causas de la enfermedad.

Los agentes piensan las distintas vías de entrada de la enfermedad atribuyéndola a una multiplicidad de causas que podríamos organizar típicamente en tres: las heridas producidas en la infancia, los pecados y excesos cometidos por los fieles, y las causas de origen estrictamente orgánico. La primera de las vías de entrada de la enfermedad y el mal, y la más expandida, es la de las heridas de la infancia: abusos sexuales y psicológicos, falta de cuidados y de amor. Un sacerdote lo define de la siguiente manera:

Normalmente cuando la gente viene a esto es porque ha entrado en áreas de pecado en el orden de la fe, pero no solo eso. Las puertas también se abren con heridas, traumas psicológicos, abusos sexuales. (Padre L, sacerdote)

A las heridas psíquicas se suma el hecho de no haber podido procesar psíquica y físicamente esas heridas: los sentimientos negativos generados-odio, rencor, dolor- enferman el alma y el cuerpo, y se convierten en pasajes para el ingreso de influencias maléficas. El padre $B$ lo explica de la siguiente manera:
...hay muchos tipos de heridas, muchos tipos. Una herida común es la falta de perdón. Pasó algo y no perdono... Pero también no perdono a Dios por una pér- dida de una mamá, un hermano, de un esposo, de un hijo y eso bloquea. El no perdón bloquea la persona. Entonces no circula tanto la gracia. (Padre B, sacer- dote exorcista)

Los pecados y excesos cometidos por los fieles son también causa de ingreso del mal y la enfermedad en la persona. No se trata solo de transgresiones de origen sexual, sino también de "acciones pecaminosas" relacionadas con "poner la fe fuera de Jesucristo"(31), sean estas realizadas de manera consciente o inconsciente. La práctica de distintas disciplinas espirituales, la consultación de adivinos y videntes, el recurso a sesiones de reiki, yoga y la práctica de ocultismo, y la más grave, la ejecución de pactos con demonios son formas ciertas de atraer sobre sí espíritus malignos. Juan, asistente de un exorcista, lo explicita:

\footnotetext{
Mucha gente va al reiki y demás, lo cual deja vulnerable totalmente a la persona, el espíritu de la persona..., entregándose para el diablo... Se piensan que yendo una hora a respirar o a hacer reiki pueden tener una pureza espiritual y les
} 
puede hacer bien al cuerpo, cuando en realidad los lleva... a licuar mucho la fe... y también las lleva al mal. (Juan, asistente del padre A)

La tercera de las entradas del mal y la enfermedad son las causas orgánicas. Los sacerdotes, sus asistentes y los consultantes describen todo un abanico de malestares en relación directa con la biomedicina (causas orgánicas, agentes patógenos). El psiquiatra que trabaja con el padre A sostiene:

Yo veo pacientes que vienen porque [dicen que] tienen un espíritu que los domina, que les habla, que les dice cosas, casi vos podés decir con un 99,9\% de seguridad que es un psicótico con alucinaciones auditivas o visuales. [Sin contradecirlo] le digo yo te voy a dar este remedio que es un antipsicótico, ni le digo que es un antipsicótico... Ese es el trabajo de la psiquiatría. (Iván M, psiquiatra)

La interpretación sobre los orígenes de la enfermedad proviene tanto de la etiología médica como de la demonología católica. Las explicaciones sobre el origen del mal conviven, se articulan y funcionan en conjunto: la duda sobre creer o no creer está presente en las personas, sobre todo en aquellos sujetos más periféricos al campo, como los consultantes ocasionales o los recién llegados a los grupos. Las causaciones múltiples que Evans Pritchard ${ }^{(33)}$ encontraba entre los azande para explicar sus malestares y desgracias, a la vez naturales y sobrenaturales, funciona en el campo de los exorcistas, sus asistentes y los consultantes: las enfermedades suceden debido a una combinación de causas, a la acción de entidades sobrenaturales y de agentes patógenos, y el énfasis en una u otra explicación depende de los casos y de las circunstancias. Existe una asociación entre la enfermedad y el mal que es notoria sin ser exclusiva: el mal, tomando forma de espíritus varios (ángeles caídos o demonios, almas condenadas, maldiciones $)^{(31)}$, perturba a la persona entrando en ella. Como veremos en el próximo apartado, tanto si la causación del malestar se atribuye a la acción de espíritus malignos como a causas naturales, el proceso de curación debe considerar el cumplimiento de prácticas religiosas y de vida sana para ser considerado exitoso.

La noción de persona no solo abarca el cuerpo, la psiquis y el espíritu, sino que amplía sus límites hasta incluir a familiares y amigos del sujeto, y a sus antepasados. El entorno puede enfermar y los padecimientos se transmiten de generación en generación: la persona es también su comunidad, sus coetáneos -la línea horizontal y sus ancestros- el linaje vertical. Ese entorno afecta su salud. La psicóloga que trabaja con el padre $B$ describe un paciente al que trató junto con el exorcista:
...el entorno de esta persona estaba enfermo obviamente. La persona con la que estaba, estaba enferma, de hecho, ya la había citado a la pareja de esta paciente. Una persona enferma, peli- grosa, de hecho, después hizo trata- miento y dejó. Manipulaba y un montón de cosas que también quiso hacer con ella. (Amalia, psicóloga y psiquiatra)

Las enfermedades se transmiten de generación en generación. $Y$ no se trata solo de una transmisión genética -como vimos, los sujetos no niegan los principios biomédicossino intergeneracional: las enfermedades, pero también los pecados vividos por las generaciones anteriores pueden reaparecer bajo otras formas en la generación actual. Amalia, la psicóloga, nos cuenta otro caso, también atendido junto con el padre B, en el cual ayudaron a un paciente

\footnotetext{
...a liberarse, y no era nada fácil, [de sus] ancestros. Pareciera como que eso se va transmitiendo de generación en generación porque a veces uno lo recibe sin tener nada que ver. (Amalia, psicóloga y psiquiatra)
} 
Dezzi, psiquiatra, afirma que

...el cuerpo tiene sus propias leyes biológicas, transmitidas de generación en generación. Son las leyes de la herencia, las cuales cobran verdadera importancia no sólo en la transmisión de enfermedades sino en actitudes y gestos transmisibles. ${ }^{(34)}$

La persona se concibe más allá del cuerpo biológico, y se extiende hacia los planos psíquico y espiritual y hacia las generaciones pasadas, que legan las particularidades de esos planos -actitudes, gestos- a las generaciones presentes.

En suma, las teorías nativas sobre la persona trascienden los límites del cuerpo, ampliándolo. Enfermedad y malestar no se limitan a un cuerpo enfermo, dado que el sujeto es cuerpo, psique y espíritu ${ }^{(35)}$. Pero tampoco se limitan al individuo: tanto el origen de la enfermedad como las formas de sanarla pueden ubicarse también en el entorno de la persona y descender de sus antepasados.

El lenguaje genético en la definición del origen de las enfermedades, analizado por Steil ${ }^{(35)}$ a partir del caso de los "demonios generacionales" exorcizados por los grupos católicos carismáticos en Porto Alegre (Brasil), revela una convergencia discursiva entre los universos religioso y médico. Más aún, el principio de la transmisión hereditaria de males y valores morales y espirituales ${ }^{(35)}$ remite a los imaginarios de los procesos de enfermedad-cura en las sociedades occidentales contemporáneas: para poder acceder a un estatuto de escucha legítima, lo religioso debe hablar el lenguaje médico-científico. En el próximo apartado, trabajaremos las terapéuticas y los rituales destinados a sanar los malestares definidos de manera ampliada.

\section{Curas, terapéuticas y ritualidades}

En conexión con las representaciones sobre la persona, las terapéuticas propuestas por los sacerdotes exorcistas apuntan a sanar los niveles físico, psicológico y espiritual. Durante nuestro trabajo de campo en una parroquia de Ezpeleta, provincia de Buenos Aires, donde el padre $L$ es párroco, se realizó una campaña que llamaron "Noches de Milagros" .

La actividad se componía de tres reuniones realizadas en tres días sucesivos: sanación interior, oración de liberación, sanación física. Los tres encuentros, predicados por el padre L y otro sacerdote, muestran claramente los tres niveles en que los agentes trabajan la cura: los planos psíquico (sanación interior en términos nativos), espiritual (oración de liberación) y corporal (sanación física) se combinan en pos de un mejoramiento integral del bienestar de la persona.

El padre L, cuya formación ecléctica incluye lecturas neopentecostales, retoma en los rituales de sanación y liberación las cosmovisiones basadas en la guerra espiritual provenientes de estas tradiciones. En este marco, el cuerpo de los fieles y el territorio en el que se inserta la parroquia son entendidos como campos de batalla donde se combaten guerras espirituales en las que se pone en juego la lucha por lo sagrado(36).

Los fieles que Ilegan a atenderse con los sacerdotes exorcistas y sus equipos suelen arribar luego de un largo recorrido terapéutico en el que se suceden agentes del campo "psi" y especialistas religiosos y espirituales: relatan consultas previas a médicos, psicólogos y curanderos. Al momento de su contacto con el sacerdote exorcista ya han desarrollado una experiencia de "sufrientes" que les permite profundizar en interpretaciones sobre su enfermedad y posibilidades de cura. La Ilegada al sacerdote suele estar mediada por alguna persona del entorno del sufriente quien le sugiere que podría ser una solución. Es importante destacar que quienes consultan a un exorcista suelen ser católicos bautizados, con mayor o menor cercanía a la práctica regular: el contacto con el sacerdote se establece a través del boca a boca. Entre los consultantes, notamos una cierta correspondencia territorial con la parroquia aunque, a medida que el sacerdote se hace más conocido, su rango de alcance territorial crece, primero en la zona de residencia y luego más allá de esta. 
Los sacerdotes exorcistas atienden secundados por un equipo ${ }^{(9,28)}$. Este grupo de asistentes colabora con las tareas de organización de los turnos y de atención y escucha. Si los asistentes sospechan un problema más grave, lo derivan al exorcista. La entrevista suele desarrollarse según un esquema organizado y relativamente fijo: comienza con una consulta sobre los síntomas y los tratamientos médicos, psicológicos o psiquiátricos realizados, y sobre la vida de fe del consultante. Bernadette, integrante del equipo del padre $\mathrm{C}$ describe el proceso:

...primero anotamos [en la ficha] todo lo que es el motivo de la consulta, por qué esa persona consulta y a veces es porque le han pasado cosas raras en la casa, o le han pasado cosas raras a ellos, cosas que no tienen explicación...Anotamos todos los síntomas que aparecen y ahí empezamos como a indagar un poquito más, cómo es la vida de fe, si son bautizados, si tomaron los sacramentos y una vez que vemos más o menos cuál es su realidad generalmente son personas que se han alejado de la iglesia ¿no? Una vez que vemos un poquito eso empezamos a preguntar si hubo algún contacto con el esoterismo porque tenemos que tratar de descubrir cuál es la puerta de entrada. (Bernadette, asistente del padre C)

La búsqueda de la causación de los síntomas suele ser central en la primera entrevista. Si el exorcista o sus asistentes identifican enfermedades que deben ser tratadas por el sistema biomédico insisten en que el paciente consulte a su especialista. En caso de tratamientos psicológicos o psiquiátricos interrumpidos el consejo es el mismo. Si se determina alguna influencia espiritual maligna, se pasa al momento que podríamos denominar como prueba/confirmación. El sufriente es expuesto al contacto con símbolos, prácticas y objetos sagrados $y$, si reacciona violentamente, su estado se ve confirmado. Los sacerdotes recurren a varios procedimientos: exhibir varias estampitas, una de ellas bendecida, para comprobar si el sufriente reconoce $y$ ataca la bendecida, orar en silencio, invocando el nombre de Jesús, para percibir transformaciones o agresiones por parte del paciente, tocarlo con agua bendita para observar reacciones adversas ante el símbolo sacro. La animosidad frente a la oración y los objetos sagrados es considerada un signo de la presencia de espíritus malignos no solo en el catolicismo, sino también en el pentecostalismo y el neopentecostalismo, así como la interacción de agentes humanos y no humanos identificados con el universo umbanda, a los que se atribuye un sentido simétrico al diablo cristiano entendido como la encarnación del mal ${ }^{(14,15,16)}$.

El momento del diagnóstico/discernimiento es considerado central por los exorcistas, porque les permite decidir qué tipo de terapéutica seguir ${ }^{(10,28)}$. Durante este proceso, el sacerdote combina saberes de orden teológico con habilidades de escucha e intuiciones sobre conocimientos médicos y psiquiátricos. Los asistentes del padre A asocian la fuerza extraordinaria de las mujeres poseídas con el fenómeno "del sansonismo, es una fuerza sobrenatural; tiene fuerza y además se pelean porque los diablos tienen distintas categorías también" (Carlos, asistente del padre A). La exhibición de fuerza sobrehumana, el conocimiento de cosas ocultas, y la comprensión y el habla en idiomas desconocidos son tres de los signos a través de los cuales el Catecismo de la Iglesia católica reconoce la posesión. Pero el conocimiento canónico y bíblico no son los únicos recursos que los exorcistas despliegan. El diálogo con discursos y textos provenientes del protestantismo -identificados por Uribe ${ }^{(37)}$ y Ospina Martínez ${ }^{(38)}$ en el contexto colombiano y con elementos del circuito espiritual alternativo o Nueva Era- están fuertemente presentes. Identificar la agencia de seres espirituales y distinguir los síntomas de enfermedades psiquiátricas demanda a los exorcistas y sus equipos una combinación compleja de habilidades y conocimientos, recursos que provienen tanto de los saberes "psi" como del campo religioso y espiritual( ${ }^{(10,11,13,16,18)}$.

El padre $C$ explica, por ejemplo, que el discernimiento es un proceso en el cual 
...hay que recorrer un camino... este camino que se va recorriendo con la persona, se trata de escuchar primero, de escuchar a su entorno, de acompañar, de contener, de brindar caminos... de acompañamiento, si hiciera falta (Padre $\mathrm{C}$, sacerdote exorcista).

El padre A, interesado desde siempre en "la psiquiatría, la psicología, la parapsicología", afirma:

...yo me doy cuenta... Me habla por teléfono un muchacho y yo digo: esquizofrenia, ya lo sé... La esquizofrenia es la enfermedad mental más rápida de discernir, porque es la única que tiene elocuciones auditivas que dicen lo que tiene que hacer... El que oye voces es esquizofrénico y, el otro, el paranoico, es el que tiene delirios de persecución sistematizada. (Padre A, sacerdote exorcista)

Otra posibilidad, a la que no todos los exorcistas recurren y que está cuestionada por algunos agentes del mismo campo (el psiquiatra que trabaja con el padre A, por ejemplo), es la realización de rituales diagnósticos, es decir, la celebración del exorcismo para constatar si hay reacción por parte de las entidades que poseen. Esta práctica está basada en la teoría que sostiene que los demonios que asedian o poseen al sufriente se ven compelidos a reaccionar ante el ritual.

La expulsión de demonios está tipificada en el Catecismo de la Iglesia católica que, en 1999, promulgó el nuevo ritual de exorcismo que reemplazó al de 1614. Presente en los textos evangélicos, la figura del diablo y las maneras de expulsarlo no gozaron hasta la temprana modernidad de una gran difusión. Durante la Edad Media, Satanás era un personaje cotidiano y la demonología una preocupación mayoritariamente erudita: recién en los siglos XVI y XVII aparece el gran miedo al diablo de la mano de las crisis religiosas y morales que vive la Europa moderna. Este terror se precisa y se difunde a través de los tratados de demonología y brujería, cuya circulación se vuelve posible gracias a la imprenta ${ }^{(39)}$. La presencia más fuerte del diablo en la escena pública en occidente (Europa y América) se concentra en los siglos XVI y XVII. Luego, los procesos de racionalización que trabajan la sociedad y la Iglesia ${ }^{(40)}$ van arrinconando a la figura demoníaca a espacios sociales circunscriptos, como la Ilamada "religiosidad popular" y el espacio limítrofe entre la religión y la expresión de los malestares físicos y psíquicos ${ }^{(41)}$. La reaparición de la figura del diablo en el centro de las prácticas de grupos religiosos diversos desde mediados de la década de 1980 se ha constatado tanto en la tradición católica ${ }^{(9,10,11,13,25,28,37,38)}$ como evangélica ${ }^{(14,15,16,26,27)}$. Asociado a las prácticas carismáticas y pentecostales, difundido por crisis económicas, morales y sociales, e impulsado por la autonomización de la construcción de las creencias, el imaginario satánico se hace presente en las primeras décadas del siglo XXI.

En la tradición católica, el exorcismo solo debería ser realizado en caso de una posesión probada, con intervención de médicos y psiquiatras. Sin embargo, podemos constatar un uso extendido de prácticas rituales que, sin llegar a recurrir al ritual del exorcismo, se le acercan en algunas de sus formulaciones: la oración de sanación y la oración de liberación usan partes del ritual del exorcismo sin llegar a las exhortaciones imprecativas ("Vete Satanás"). También se recurre a soportes materiales igualmente presentes en el ritual de exorcismo: agua bendita, sal exorcizada, aceite ungido, la cruz y el rosario.

El padre $\mathrm{C}$ describe la práctica en toda su indeterminación de manera clara:

...acá no hay que buscar ninguna cosa ni mágica, ni truculenta, son... es la palabra de Dios, son salmos, son oraciones, letanías a los santos, invocaciones a la Virgen santísima $y$, fundamentalmente, dos tipos de oraciones que se llaman oraciones exhortativas y oraciones invocativas, donde se pide a Dios, en primer lugar, que si hubiera una presencia o si estuviera ejerciendo algún tipo de influencia, con alguna presencia maligna en una persona, se termine, y 
después si apareciera esa influencia de forma manifiesta el exorcismo prevé en su oración esta oración exhortativa, en donde en nombre de Dios, esto insisto, el único que expulsa al espíritu del mal es Dios. (Padre C, sacerdote exorcista)

En los rituales, sean éstos de exorcismo o de liberación, las personas pueden expulsar fluidos del cuerpo (llanto, toses y arcadas, vómitos, objetos extraños): es esta tanto una metáfora del corte de la opresión/posesión a partir de la salida concreta del cuerpo de elementos varios, como un signo del inicio del proceso de liberación/sanación. Ahora bien, los espíritus que poseen, y que pueden entrar y salir del cuerpo, no son solo espíritus del mal. De hecho, para concretar la sanación del sufriente, el cuerpo debe expulsar los espíritus malignos - “inmundicias"(31) - y dejar penetrar al Espíritu Santo. Es el Espíritu Santo, una de las tres formas del Dios trino para la teología católica, el que sana tanto afecciones físicas como psicológicas y espirituales ${ }^{(38)}$.

Durante las misas de sanación física y de liberación uno de los segmentos más fuertes es el momento en que se invoca al Espíritu Santo, tanto durante la misa, en la oración y la "pasada del Santísimo", como luego de esta, cuando los sacerdotes imponen las manos y oran sobre los fieles (Figura 2).

Así como la persona es permeable porque está abierta a las influencias maliciosas, también lo es porque puede abrirse al bien y a la acción divina. María, fiel de la parroquia del padre L, nos cuenta que había hecho pactos con entidades maléficas, y describe así el momento en que se sintió sanada:

Yo sentí que en ese momento Dios ponía su mano dentro de mi cuerpo, dentro de mi corazón y sacaba todo lo que no estaba bueno y sacó mucho, porque yo sentí el desprendimiento y sentí que, a su vez, salía lo malo, pero entraba un amor que...y eso, solamente lo hace Dios. (María, laica comprometida en la parroquia del padre L)
El cuerpo es permeable y es por eso que, durante la imposición de las manos, en el momento en que el sacerdote reza tocando la cabeza de la persona, muchos fieles caen al piso, como inconscientes, otros Iloran cuando se acerca la hostia consagrada. La interpretación nativa sostiene que el Espíritu Santo está actuando en ellos para sanarlos ${ }^{(1,2)}$. Estela lo explica con sus palabras:

[el sacerdote] me puso los dedos en los ojos... Y no me acuerdo más nada, cuando me desperté estaba tirada en el piso, sentí como que algo, sentí una fuerza, una fuerza que yo no tenía, sino que algo que me ablandó, que me dejó tirada. Dicen que es el Espíritu Santo que entra en tu cuerpo y actúa. (Estela, fiel de la parroquia del padre C)

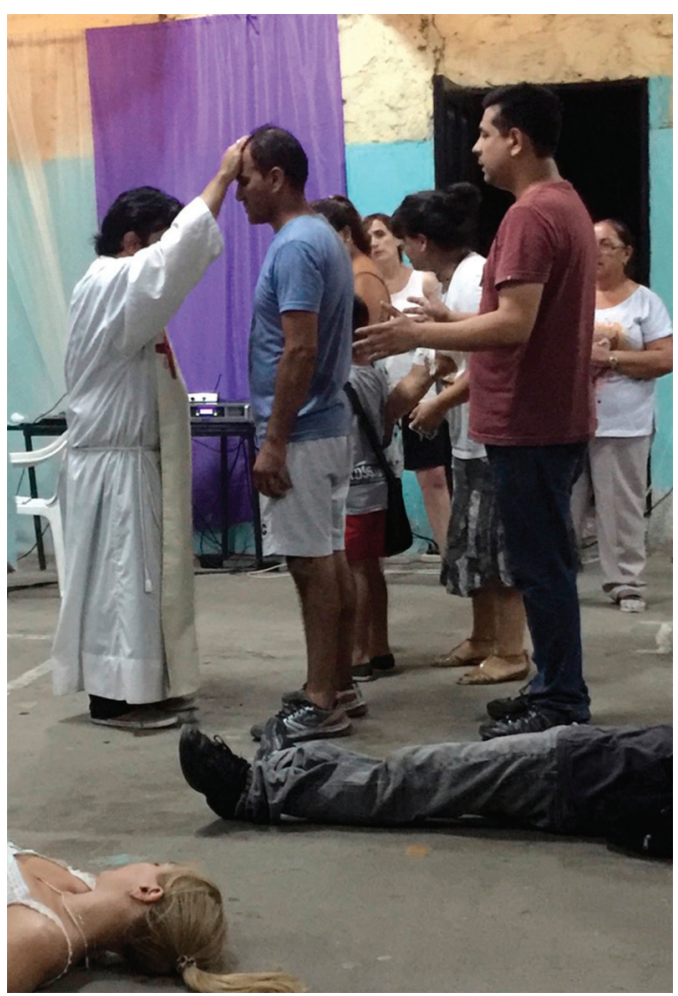

Figura 2. Sacerdote imponiendo las manos al término de una misa de sanación. Ezpeleta, Buenos Aires, 26 de febrero de 2016.

Foto: Verónica Giménez Béliveau.

Nota: En la imagen pueden verse las personas caídas, luego de la práctica ritual. 
Los sacerdotes, sus asistentes y los agentes de salud lo destacan con unanimidad: los casos de posesión son extremadamente raros. El padre $C$ explica que

...el Demonio puede tomar posesión de una persona, caso verdaderamente rarísimo, insisto, rarísimo, yo llevo en esto 8, 9 años y no tuve nunca un caso de posesión demoníaca, y atiendo a 30, 40 personas que vienen a hacerse un diagnóstico, con todo un equipo de profesionales, psiquiatras, psicólogos, counselors, médicos, etc. (Padre C, sacerdote exorcista)

Ellos mismos identifican, sin embargo, una serie de perturbaciones que atribuyen a la acción de los espíritus: tentaciones, opresiones, vejaciones, infestaciones, obsesiones, posesiones, que afectan la voluntad, los sentimientos, el cuerpo -desde afuera o desde adentro-, los ambientes o animales, la imaginación ${ }^{(42)}$. Las formas terapéutico-rituales para enfrentar esta serie de problemas son del mismo tipo, y se ubican en un arco en cuyo extremo encontramos el ritual del exorcismo. Oraciones de sanación y de liberación, misas de sanación intergeneracional, plegarias por la sanación de las generaciones pasadas son las prácticas que los sacerdotes proponen a los consultantes para cerrar el proceso de cura.

La propuesta terapéutica de los sacerdotes es compleja y articula diversos niveles de acción: la derivación a médicos, psicólogos y psiquiatras, cuando entienden que es necesario, la recomendación de una higiene de vida sana, y la propuesta de (re)integración a la comunidad católica. La necesidad de recurrir al sistema biomédico es enunciada por los sacerdotes y sus asistentes en todo momento: durante la entrevista de diagnóstico preguntan por los tratamientos que la persona sigue, luego de los rituales exigen que continúen con sus tratamientos, en las publicaciones se reitera la necesidad de consultar al médico:

Es fundamental, durante cualquier proceso de liberación, continuar con los tratamientos o medicinas recetadas por los médicos, tanto en el orden físico (médico especialista) como psíquico (atención por psicólogo o psiquiatra). ${ }^{(32)}$

Estas recomendaciones también son reiteradas en público, durante las misas, en los grupos de oración y campañas de sanación. "Dios usa a los médicos, por eso hay que visitar al médico", sostuvo el padre L en una misa, ante alrededor de 200 personas en Ezpeleta (registro de campo). Los agentes no disputan sentidos contra el sistema biomédico, articulan sus prácticas con él, integran las perspectivas médica y espiritual, ubicándose en uno de los polos sin negar el otro.

Sin embargo, el seguimiento médico no Ilega a completar el proceso de sanación. El afectado debe mantener una higiene de vida acorde con sus deseos de sanación en todos los planos. Estos argumentos están presentes en la mayoría de las conversaciones con exorcistas y sus asistentes, pero es el padre L, en la misa de sanación física, en abril de 2017, quien lo enuncia con mayor contundencia: incita a llevar una "vida ordenada, porque una vida de orden trae salud, también salud mental" (registro de campo).

La vida ordenada tiene que ver con varios procesos: la regulación de los excesos en la comida y la bebida -que el sacerdote comenta poniéndose como ejemplo luego de haber adelgazado varios kilos- y la regulación de la sexualidad. Las prácticas sexuales aceptadas se dan en el marco del matrimonio religioso y son heterosexuales. Sin embargo, no es el único tipo de práctica recomendada para alinearse con el orden moral: controlar la ira y la violencia, combatir la pereza y, sobre todo, emprender una verdadera vida de fe y de (re)integración a la comunidad eclesiástica. "Para sanarnos, tenemos que hacer un camino serio de conversión", afirma el padre L en la misa (registro de campo). Este camino comienza con la adopción de normas de vida sana: buena alimentación, ejercicio físico y descanso adecuado.

Una vida moral y religiosamente regulada no puede separarse de la integración a la comunidad religiosa: se trata de un mismo 
movimiento, a través del cual la persona vuelve a tener un encuadramiento religioso adecuado y adopta normas que la alejan de las situaciones de peligro ${ }^{(35,36)}$. Veamos dos descripciones del proceso de cura/sanación/ integración realizado por los agentes de cura, un sacerdote y un psicólogo católico:

Mucha gente no viene con una catequesis adecuada, con una formación adecuada, vienen con las ideas muy entremezcladas, y con ciertas confusiones... Es suficiente con acompañar catequísticamente a la persona, ver cómo son sus vínculos afectivos, familiares, laborales, qué es lo que inquieta a la persona en su entorno, cuáles son sus heridas, ahí tienen que intervenir los profesionales psicólogos y psiquiatras y, dada esta contención, esta capacidad de escucha, es ir llevando a la persona que, si elige abrirse a Dios, Dios no la va a abandonar. $Y$ ese solo cambio de perspectiva en la persona ya la hace ponerse frente a Dios, y no de cara al mal, en sus propios miedos y confusiones. (Padre $\mathrm{C}$, sacerdote exorcista)

El psiquiatra Dezzi ${ }^{(31)}$, a su vez, afirma:

...estos enfermos deambulan [...], nosotros debemos tratar de contenerlos, de pastorearlos y ayudarlos. El tratamiento consiste en, [primero], incorporarlos a la Iglesia y hacerles saber que se liberarán de Satanás en los tiempos de Dios. Tratar de encontrar la puerta de entrada, la acción, el pecado grave que abrió la puerta del alma (el inconsciente parapsicológico) y exigirle una confesión general [...] Como médico psiquiatra y laico considero que el diagnóstico clínico de un paciente oprimido-poseído por el diablo es fundamental, es el primer paso. Luego, debemos brindarle contención dentro de la Iglesia, acompañamiento; pedir oración a quienes se dedican a ella como misión dentro de la Iglesia. $Y$ aconsejarle que haga un camino de conversión y de seguimiento del Señor [...] Cuando la persona está infectada, requiere asistencia médica y espiritual para volver a su estado de salud.

En las propuestas terapéuticas, así como en las concepciones de la persona, la articulación con el discurso médico-científico es permanente. La interacción entre conceptos provenientes de un campo y del otro convergen en un discurso que no solo no los presenta como contradictorios, sino que los integra complementariamente: las dos esferas funcionan juntas. Además, es importante destacar que estas no solo se dirigen al individuo: respondiendo a las concepciones de la persona de los consultantes, los exorcistas y sus asistentes, la acción de cura debe cumplirse también en el entorno de la persona. Durante un retiro de evangelización, el padre L guía una plegaria destinada a sanar los vínculos familiares. Allí sostiene que:

[en este momento] se rompen las cadenas, se rompen las ataduras, se quiebra todo mal sobre mi familia. Vamos a orar ahora por los hogares, si hay alguna perturbación en tu hogar vamos a rezar para que tu hogar sea bendecido también. Los que no están, tu hijo, esposo, novio, novia, pero lo más importante es que vos ores..., es importante que vos abras los labios y hagas vos tu oración: bendice mi casa Señor, bendice a mis hijos, mi esposo, todos mis seres queridos, derrama tu bendición sobre mi hogar, derrama tu bendición sobre mi familia, en tu nombre poderoso Señor yo anulo, cancelo, corto toda influencia del mal espíritu sobre mi familia, sobre mis finanzas, sobre mi salud. Vamos a orar por los hijos... si tenés a tus hijos en la droga, en el alcohol, pedile a Dios: Señor, libera a mi hijo, te lo entrego. (Registro de campo)

Como sostiene Ribeiro ${ }^{(14)}$, en el funcionamiento discursivo que rige la interlocución entre el sacerdote, Dios y los fieles, se observa que la palabra del sacerdote posee diversos poderes performativos: el sacerdote es, al mismo tiempo, árbitro de las interlocuciones, 
agente que controla los cuerpos de los fieles y sujeto productor de diferentes imágenes sobre las relaciones sociales y familiares en términos de alteridad-identidad, puestas en relación durante la práctica ritual. Las palabras del sacerdote son percibidas por los fieles como guiadas por la intervención y el poder del Espíritu Santo, de este modo los fieles visibilizan la presencia de lo sagrado en los cuerpos de los sacerdotes, legitimando así sus discursos y sus prácticas.

El proceso de sanación supone no solo liberar el cuerpo, la mente y el espíritu de los fieles: debe también llegar a los familiares. El entorno del consultante debe ser sanado, y esto se logra gracias a las prácticas rituales de integración a la comunidad del fiel y de su familia que, idealmente, debería seguir al consultante, y a la adopción, como vimos, de un conjunto de reglas prácticas y morales que se extiende a quienes rodean al sujeto.

El trabajo terapéutico sobre la línea horizontal -familiares, amigos- del consultante se completa con la acción sobre el linaje: las generaciones pasadas deben ser repensadas, para así "sanar el árbol genealógico" (registro de campo). Este proceso se realiza tanto en oraciones que se incluyen en retiros espirituales y misas de sanación, como también en eventos especiales, como el Seminario de Sanación Intergeneracional que la Hermana Inés Brown dicta en distintas parroquias de Argentina. El esquema ritual propuesto en el Seminario supone momentos de oración y de prédica, y momentos de reflexión de cada uno de los participantes sobre su ascendencia y "las enfermedades, los pecados y los vicios" de los ancestros. El soporte elegido para la reflexión se condensa en un árbol genealógico en blanco, que debe ser completado por los participantes con los nombres de sus antepasados y los vicios/enfermedades/pecados de cada uno de ellos (Figura 3): este trabajo se realiza sobre la propia ascendencia y sobre el linaje del cónyuge.

Al finalizar los tres encuentros del seminario, y durante una misa, se juntan todos los árboles genealógicos y se los ubica sobre el altar, con el objeto de "cortar los vínculos nocivos" (registro de campo). Este instrumento

\section{Genograma}

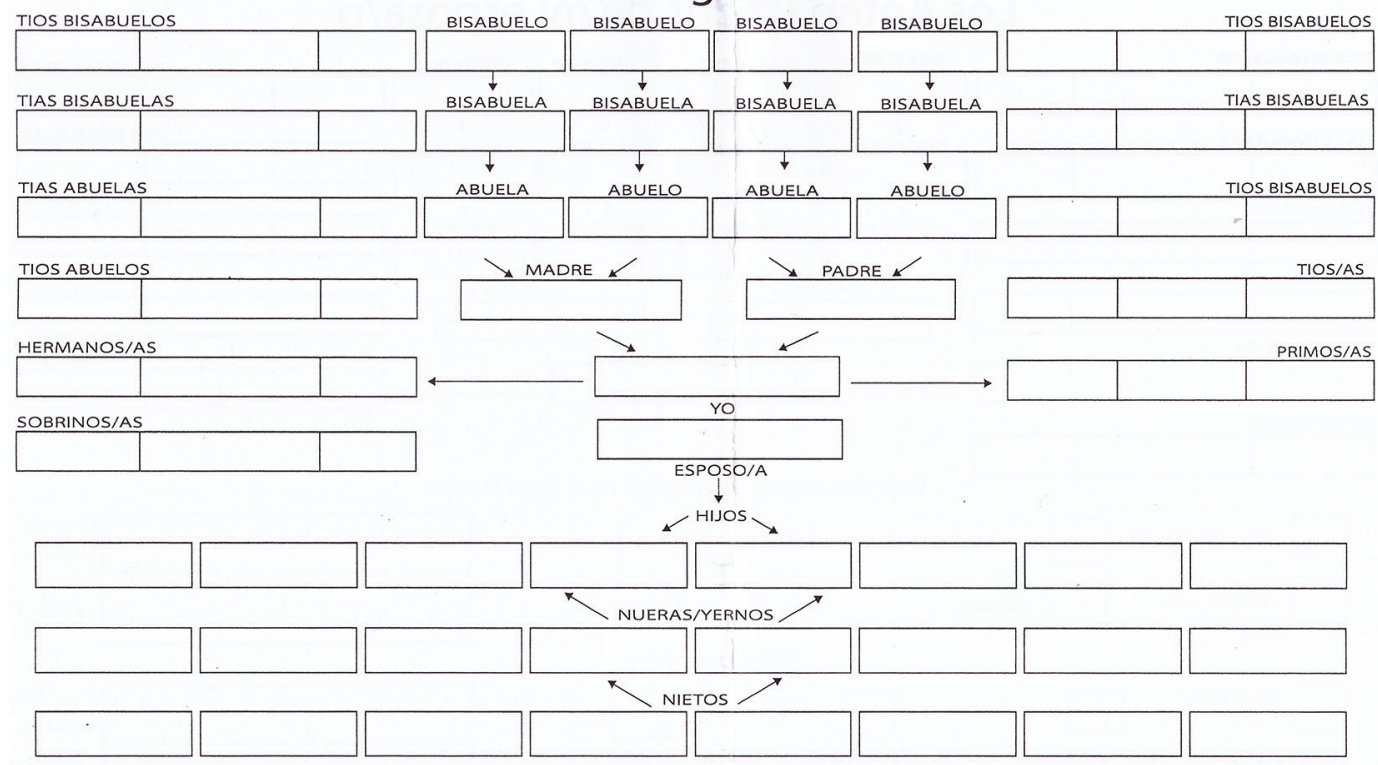

Figura 3. Genograma: instrumento de trabajo distribuido en el Seminario de Sanación Intergeneracional, dictado por la Hermana Inés Brown. Octubre de 2015. 
tiene sorprendentes similitudes con el genograma utilizado por las terapias familiares para identificar conflictos no resueltos, agresiones no procesadas, problemas en la familia y los antepasados del paciente ${ }^{(43,44)}$. Nuevamente, el diálogo con el sistema médico-científico es central en la elaboración y concreción del proceso terapéutico ${ }^{(35)}$. Los instrumentos de recolección y organización de los datos del paciente/consultante tienen formas parecidas, y apuntan a una concepción de base que funciona en los dos campos: las acciones de los antepasados pesan sobre el presente de los sujetos, y es posible realizar intervenciones terapéuticas para restablecer el bienestar sobre la persona y el linaje.

\section{CONCLUSIONES}

Nuestro recorrido a través de la concepción de la persona, la enfermedad y las terapéuticas en grupos católicos ligados a las prácticas de liberación y exorcismos nos llevó a comprender que esta demanda responde a una serie de malestares situados en distintos niveles de la sociedad contemporánea -físicos, psicológicos, relacionales-, y se sostiene en concepciones ampliadas de la persona, la salud y el bienestar. Volver a la salud supone una serie de procesos terapéuticos en los que la higiene de vida y las prácticas rituales se articulan en busca de un estado de bienestar. Los discursos y las prácticas, lejos de remitir a referencias eclesiales pretéritas dialogan, sobre todo, con discursos pilares de la sociedad contemporánea: el discurso científico-médico, especialmente en sus ramas psicológica y psiquiátrica ${ }^{(37,38,45)}$, y otros discursos relacionados con las creencias que podríamos relacionar con la Nueva Era ${ }^{(46)}$.

Tanto en el espacio discursivo como en la organización de las prácticas, la interrelación con los términos médicos estructura las emisiones: las personas son "infectadas" por bacterias y por malos espíritus, los exorcistas "diagnostican" el grado de influencia o no de los demonios, se invita a los consultantes a adoptar una higiene de vida que mezcla consejos sobre cómo gestionar la alimentación, el ejercicio físico y el descanso con la integración a la comunidad religiosa y la recuperación de prácticas rituales regulares. El esquema de incorporación al tratamiento se construye en espejo con el de la medicina: pedir turno, realizar entrevistas con distintos agentes (algunos, incluso, son agentes de salud), realización del diagnóstico/discernimiento, tratamiento posterior. El énfasis puesto en el diagnóstico y la insistencia en los procesos racionales que se juegan allí, muestran la centralidad del diálogo con la medicina científica ${ }^{(47)}$. Los sacerdotes exorcistas arman equipos que se ubican en un espacio de intersección entre los campos espiritual y médico. Este tipo de prácticas responden, por otro lado, a una demanda amplia que las instituciones médicas y de asistencia del sistema público y privado no llegan a cubrir.

A partir de la comprensión de los procesos de sanación y liberación en el cruce de cosmovisiones diversas, las prácticas terapéuticas se constituyen desde una pluralidad no siempre asumida, pero claramente presente: como en las espacios de medicina alternativa en hospitales estudiados por Saizar y Korman ${ }^{(48)}$ a partir del concepto de "complementariedad terapéutica", como en las prácticas de los exorcistas ${ }^{(10)}$, los agentes de cura y sus pacientes recurren a un universo plural de sentidos y acciones para tratar de enfrentar malestares definidos de manera amplia, con recursos múltiples, y logran expresar en un lenguaje religioso y espiritual malestares que se ubican en el campo de intersección entre religión y salud. 


\section{AGRADECIMIENTOS}

Las autoras agradecen la generosidad de los/as evaluadores/as anónimos/as que leyeron con interés y agudeza la primera versión de este artículo. Sus comentarios y observaciones nos permitieron mejorar el texto.

\section{REFERENCIAS BIBLIOGRÁFICAS}

1. Cabrera P. Nuevas prácticas, nuevas percepciones: la experiencia de la Renovación Carismática Católica. ILHA Revista de Antropologia. 2001;3(1):121-137.

2. Giménez Béliveau V. Católicos militantes: sujeto, comunidad e institución en la Argentina. Buenos Aires: Eudeba; 2016.

3. Kleinman A. Writing at the margin: discourse between anthropology and medicine. Berkeley: University of California Press; 1995.

4. Schepere-Hugues N. La muerte sin Ilanto. Barcelona: Ariel; 1996.

5. Ginzburg C. I benandanti: ricerche sulla stregoneria e sui culti agrari tra Cinquecento e Seicento. Torino: Einaudi; 1966.

6. Ginzburg C. Storia notturna: una decifrazione del sabba. Torino: Einaudi; 1989.

7. De Certeau M. La possession de Loudun. Paris: Folio-Gallimard; 2005.

8. Messana MS. Inquisitori, negromanti e streghe nella Sicilia moderna: 1500-1782. Palermo: SeIlerio; 2007.

9. Talamonti A. La carne convulsiva: etnografía dell'esorcismo. Napoli: Liguori; 2005.

10. Amiotte-Suchet L. Un ministere de bricolage rituel: le cas d'un exorciste diocésain. EthnologieFrançaise. 2016;161(1):115-126.

11. Giordan G, Possamai A. Branding the devil in New Age and catholicism: a Sociology of Exorcism. Religioni e Società. 2016;86:90-98.

12. Csordas TJ. Body/meaning/healing. New York: Palgrave Macmillan; 2005.

13. Csordas TJ. Language, charisma, and creativity: ritual life in the Catholic charismatic renewal. New York: Palgrave Macmillan; 2012.
14. Ribeiro J. O simulacro da alteridade: uma análise discursiva do ritual de exorcismo da Igreja Universal do Reino de Deus. Debates do Ner. 2005;6(7):11-78.

15. De Almeida R. A guerra das possessões. En: Oro AP, Corten A, Dozon JP, organizadores. Igreja Universal do Reino de Deus: os novos conquistadores da fé. São Paulo: Paulinas; 2003. p. 67-77.

16. Semán $\mathrm{P}$, Moreira P. La Iglesia Universal del Reino de Dios en Buenos Aires y la recreación del diablo a través del realineamiento de marcos interpretativos. Sociedad y Religión. 1998;(16):95-110.

17. Tadvald M. Exorcismo e corposterritórios: notas sobre possíveis marcos interpretativos da transnacionalização religiosa. Revista NURES. 2012;8(20):1-8.

18. Tadvald M. Corpo e possessão na teodicéia racionalista do espiritismo kardecista. Ciências Sociais e Religião. 2007;9(9):117-139.

19. Ameigeiras A. El abordaje etnográfico en la investigación social. En: Vasilachis de Gialdinol. Estrategias de investigación cualitativa. Barcelona: Gedisa; 2006.

20. Guber R. La etnografía: método, campo y reflexividad. Bogotá: Norma; 2006.

21. Patton MQ. Qualitative research and evaluation methods: integrating theory and practice; the definitive text of qualitative inquiry frameworks and options. Thousand Oaks: Sage; 2015.

22. Patton MQ. Qualitative evaluation and research methods. Newbury Park: Sage; 1990.

23. Mishler EG. Research interviewing: context and narrative. Cambridge: Harvard University Press; 1991.

24. Corten A. Le pentecôtisme au Brésil: emotion du pauvre et romantisme théologique. Paris: Karthala; 1995.

25. Ospina Martínez MA. Apuntes para el estudio antropológico de la alabanza carismática católica. Convergencia Revista de Ciencias Sociales. 2004;11(36):31-59.

26. Bastian JP. De los protestantismos históricos a los pentecostalismos latinoamericanos: análisis de una mutación religiosa. Revista de Ciencias Sociales. 2006;(16):38-54.

27. Beltrán Cely WM. De microempresas religiosas a multinacionales de la fe: la diversificación del cristianismo en Bogotá. Bogotá: Bonaventuriana; 2006. 
28. Giménez Béliveau V. Terapéuticas católicas, males modernos: procesos de sanación y exorcismo en la Argentina. Sociedad y Religión. 2017; 27(47):33-59.

29. Mauss M. Sociología y antropología. Madrid: Tecnos; 1979.

30. Dezzi M. Liberación. Mendoza: Allubgraf; 2004.

31. Dezzi M. Cristo o Satanás. Mendoza: Edición del Autor; 2003.

32. Pastoral de la Consolación. Consejos pastorales contra la acción extraordinaria del Demonio y Oraciones de Sanación y de Liberación [folleto]. Buenos Aires: Diócesis de San Isidro; s/f.

33. Evans-Pritchard E. Brujería, magia y oráculos entre los azande. Barcelona: Anagrama; 1976.

34. Dezzi M. El alma humana. Mendoza: Talleres Gráficos de Inca; 2011.

35. Steil CA. Os demonios geracionais: aherança dos antepassados na determinaçao das escolhas e das trajetórias pessoais. En: Duarte LFD, Heilborn ML, Barros ML, Peixoto C, organizadores. Família e religião. Rio de Janeiro: Contra Capa; 2006. p. 51-88.

36. Tadvald M. O simulacro da alteridade em perspectiva: comentários acerca de uma análise discursiva de um ritual da Igreja Universal. Debates do NER. 2005;1(7):89-97.

37. Uribe CA, Martínez Medina S, Vásquez Rojas R, Castro C. Virginidad, anorexia y brujería: el caso de la pequeña Ismenia. Antípoda. 2006;(3):51-90. en la Renovación Carismática Católica. Universitas Humanística. 2006;61(61):135-162.

39. Zamora Calvo MJ. Artes maleficorum: brujas, magos y demonios en el Siglo de Oro. Barcelona: Calambur; 2016.

40. Weber M. Excurso: Teoría de los estadios y direcciones del rechazo religioso del mundo. Tomo 1. En: Weber M. Ensayos sobre sociología de la religión. Madrid: Taurus; 1987. p. 437-438.

41. Giordan G, Possamai A. Mastering the devil: a sociological analysis of the practice of a catholic exorcist. Current Sociology. 2017;66(1):74-91.

42. Manual de la Convivencia con Pablo. Buenos Aires: Editorial Convivencia con Dios; 2011.

43. Alfödi F. L'évaluation en protection de I'enfance: théorie et méthode. Paris: Dunod; 1999.

44. Schützenberger AA. Aïe, mes aïeux. Paris: Desclée de Brouwer; 1998.

45. Funes M. Mito y ritual: terapeutas religiosos en el contexto del catolicismo en el área metropolitana (Argentina). Mitológicas. 2007;XXII:55-68.

46. Viotti N, Funes ME. La política de la Nueva Era: el arte de vivir en Argentina. Debates do NER. 2015;2(28):17-36.

47. Corten A. Alchimie politique du miracle. Montréal: Éditions Balzac; 1999.

48. Saizar M, Korman G. Interactions between alternative therapies and mental health services in public hospitals of Argentina. SAGE Open. 2012;2(3):1-13.

38. Ospina Martínez MA. Satanás se "desregula": sobre la paradoja del fundamentalismo moderno

FORMA DE CITAR

Giménez Béliveau V, Fernández NS. "Somos cuerpo, alma y espíritu": Persona, enfermedad y procesos de sanación y exorcismo en el catolicismo contemporáneo en Argentina. Salud Colectiva. 2018;14(2):161-177. doi: 10.18294/ sc. 2018.1504

Recibido: 6 de julio de 2017 | Versión final: 28 de marzo de 2018 | Aprobado: 9 de abril de 2018

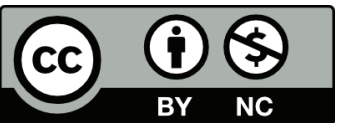

Este obra está bajo una licencia de Creative Commons Reconocimiento-NoComercial 4.0 Internacional. Reconocimiento - Permite copiar, distribuir y comunicar públicamente la obra. A cambio, se debe reconocer y citar al autor original. No Comercial - Esta obra no puede ser utilizada con finalidades comerciales, a menos que se obtenga el permiso. 